Subscriber access provided by Caltech Library

\title{
Article
}

\section{Ionic and Neutral Mechanisms for C-H Bond Silylation of Aromatic Heterocycles Catalyzed by Potassium t-Butoxide}

Shibdas Banerjee, Yun-Fang Yang, lan D. Jenkins, Yong Liang, Anton

Alexandrovich Toutov, Wen-Bo Liu, David P Schuman, Robert H. Grubbs,

Brian M. Stoltz, Elizabeth H. Krenske, Kendall N. Houk, and Richard N. Zare

J. Am. Chem. Soc., Just Accepted Manuscript • Publication Date (Web): 02 May 2017

Downloaded from http://pubs.acs.org on May 2, 2017

\section{Just Accepted}

"Just Accepted" manuscripts have been peer-reviewed and accepted for publication. They are posted online prior to technical editing, formatting for publication and author proofing. The American Chemical Society provides "Just Accepted" as a free service to the research community to expedite the dissemination of scientific material as soon as possible after acceptance. "Just Accepted" manuscripts appear in full in PDF format accompanied by an HTML abstract. "Just Accepted" manuscripts have been fully peer reviewed, but should not be considered the official version of record. They are accessible to all readers and citable by the Digital Object Identifier (DOI@). "Just Accepted" is an optional service offered to authors. Therefore, the "Just Accepted" Web site may not include all articles that will be published in the journal. After a manuscript is technically edited and formatted, it will be removed from the "Just Accepted" Web site and published as an ASAP article. Note that technical editing may introduce minor changes to the manuscript text and/or graphics which could affect content, and all legal disclaimers and ethical guidelines that apply to the journal pertain. ACS cannot be held responsible for errors or consequences arising from the use of information contained in these "Just Accepted" manuscripts. 


\section{INTRODUCTION}

More than $90 \%$ of industrial chemical processes employ catalysis. ${ }^{1}$ Most catalysts rely upon metals, often transition metals that are very expensive and may require supporting ligands, and the overall processes are not environmentally benign. Therefore, sustainable development of transitionmetal-free catalysis is highly important. ${ }^{2}$ A number of literature precedents have substantiated the usefulness of potassium $t$-butoxide $\left(\mathrm{KO}^{t} \mathrm{Bu}\right)$ as a catalyst for different types of coupling reactions. ${ }^{2-8}$ Recently, Toutov et al. ${ }^{9}$ reported the direct silylation of $\mathrm{C}-\mathrm{H}$ bonds in aromatic heterocycles, with excellent regioselectivity and good yield, by using $\mathrm{KO}^{t} \mathrm{Bu}$ as the catalyst and hydrosilanes as a convenient and inexpensive silicon source, as shown in Scheme 1. Although the initial study did not lead to a conclusive understanding of the reaction mechanism, a combined experimental and theoretical effort has helped us to conceive of two independent mechanisms (radical and ionic) that may drive the silylation reaction. It is not surprising that a reaction may have more than one mechanism..$^{10-12}$ The accompanying paper, communicated together with this manuscript, describes the radical mechanism for this reaction. We present here the ionic mechanism of the $\mathrm{KO}^{t} \mathrm{Bu}$ catalyzed silylation of heteroaromatic $\mathrm{C}-\mathrm{H}$ bonds. ${ }^{9}$ Evidence from ambient ionization mass spectrometry, conductivity measurements, and density functional theory (DFT) calculations identifies the ionic species (intermediates) present in the reaction mixture and leads to the proposal of two heterolytic mechanisms that are consistent with all reaction features previously observed by Toutov et al. ${ }^{9}$ as well as explaining possibly the sudden onset of the reaction (vide infra).

Scheme 1. The KO ${ }^{t}$ Bu-Catalyzed Silylation of Indoles

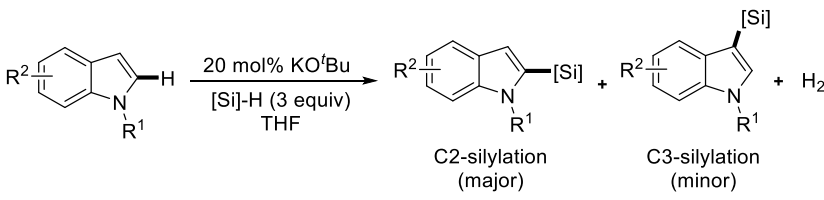

$$
\begin{aligned}
& \mathrm{R}^{1}=-\mathrm{Me},-\mathrm{Et},-\mathrm{Ph},-\mathrm{CH}_{2} \mathrm{Ph},-\mathrm{CH}_{2} \mathrm{OMe} \text { or }-\mathrm{CH}_{2} \mathrm{O}\left(\mathrm{CH}_{2}\right)_{2} \mathrm{SiMe}_{3} \\
& \mathrm{R}^{2}=-\mathrm{H},-\mathrm{Me},-\mathrm{Ph},-\mathrm{OMe},-\mathrm{OCH}_{2} \mathrm{Ph} \text { or }-\mathrm{CH}_{2} \mathrm{OMe} \\
& \text { [Si]-H }=\mathrm{Et}_{3} \mathrm{SiH}, \mathrm{Et}_{2} \mathrm{SiH}_{2}, \mathrm{EtMe}_{2} \mathrm{SiH}, \mathrm{PhMe}_{2} \mathrm{SiH} \text { or }{ }^{n} \mathrm{Bu}_{3} \mathrm{SiH}
\end{aligned}
$$

\footnotetext{
RESULTS AND DISCUSSION

Detection of Ionic Intermediates by DESI-MS. To detect the transient ionic intermediate(s) in the solution-phase reaction, we employed desorption electrospray ionization mass spectrometry (DESI-MS; see Supplementary Note 1). ${ }^{13}$ The
} 
details of the DESI-MS experimental set-up are shown in Figure S1 of the Supporting Information (SI). During the course of the $\mathrm{KO}^{t} \mathrm{Bu}$-catalyzed reaction of 1-methylindole with triethylsilane in tetrahydrofuran (THF) (Scheme 1, where $\mathrm{R}^{1}=\mathrm{Me}, \mathrm{R}^{2}=\mathrm{H}$ and $[\mathrm{Si}]-\mathrm{H}=\mathrm{Et}_{3} \mathrm{SiH}$ and see Experimental Section for details), we detected the formation of deprotonated 1-methylindole (m/z 130.0663; Figure 1a) by DESI-MS. The same ion $(\mathrm{m} / \mathrm{z} 130.0663)$ was not detected in control experiments where pure 1-methylindole or a mixture of 1methylindole and $\mathrm{Et}_{3} \mathrm{SiH}$ were analyzed (data not shown). Protons $\mathrm{C} 2$ and $\mathrm{C} 3$ in the pyrrole ring of 1-methylindole are comparatively acidic in nature. ${ }^{14}$ As the $\mathrm{C} 2$ proton is more acidic than the $\mathrm{C} 3$ proton $\left(\mathrm{C} 2\right.$ proton- $\mathrm{pK}_{\mathrm{a}} \approx 37$ and $\mathrm{C} 3$ proton$\mathrm{pK}_{\mathrm{a}} \approx 42$ in THF), ${ }^{\mathbf{1 4}}$ the $\mathrm{C} 2$ proton is expected to be preferentially abstracted by a strong base, present in the reaction medium. To verify this, we performed the corresponding reaction on C2-deuterated 1-methylindole (Figure 1b). Although the bond strength of C2-D is slightly higher than that of $\mathrm{C} 2-\mathrm{H}$, we were still able to detect the deuterium-abstracted species $(\mathrm{m} / \mathrm{z} 130.0663)$ as a major anion and the proton-abstracted species $(\mathrm{m} / \mathrm{z} 131.0749)$ as a minor anion from $\mathrm{C} 2$-deuterated 1-methylindole substrate. These results, in conjunction with the reported regioselectivity $(\mathrm{C} 2$ [Si]:C3-[Si] > 20:1), ${ }^{9}$ clearly suggest that a proton from the pyrrole ring of 1-methylindole is abstracted during the reaction, and that the $\mathrm{C} 2$ proton is preferentially abstracted relative to the $\mathrm{C} 3$ proton.

Along with deprotonated 1-methylindole, an ion signal at $\mathrm{m} / \mathrm{z} 318.2288$ corresponding to the pentacoordinate silicon species $\operatorname{ArEt}_{3}\left({ }^{t} \mathrm{BuO}\right) \mathrm{Si}^{-}$was also detected in the reaction mixture (Figure 1a). Presumably, this hypervalent silicon intermediate proceeds to form the product in the catalytic cycle. We also detected the $\mathrm{K}^{+}$complex of the product (silylated 1-methylindole) by DESI-MS under positive ion mode (Figure S2), indicating a cation- $\pi$ interaction involving $\mathrm{K}^{+}$and the ' $\pi$-excessive' indole moiety. ${ }^{15}$ In a separate DESIMS control study, we mixed pure $\mathrm{C} 2$-silylated product $\left(\mathrm{R}^{1}=\right.$ $\mathrm{Me}, \mathrm{R}^{2}=\mathrm{H}$, [Si] $=\mathrm{SiEt}_{3}$ in Scheme 3 ) and $\mathrm{KO}^{t} \mathrm{Bu}$, but we did not detect the $\operatorname{ArEt}_{3}\left({ }^{t} \mathrm{BuO}\right) \mathrm{Si}^{-}(\mathrm{m} / z$ 318.2288). This result suggests that this species is predominantly formed during the course of the reaction (Figure 1a), not by the interaction of the product and $t$-butoxide ion.

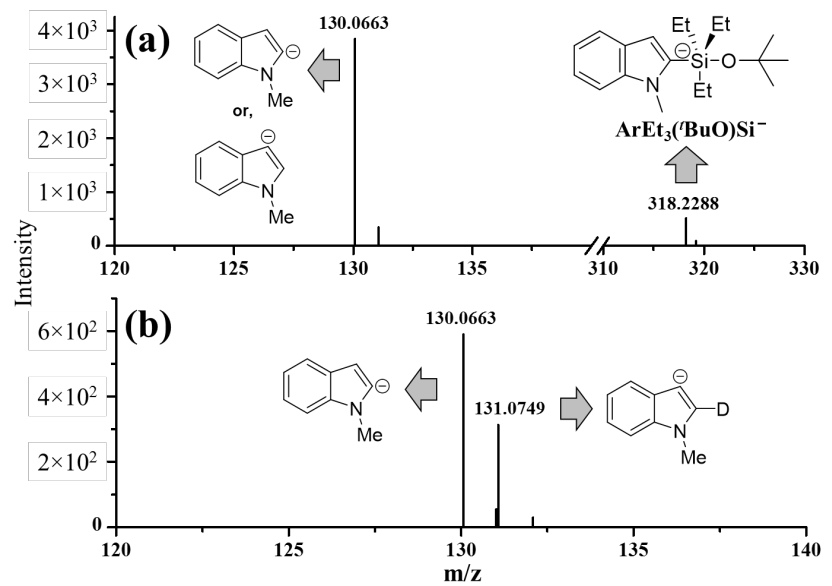

Figure 1. Negative ion mode DESI mass spectra (background subtracted) for the silylation reaction of (a) 1-methylindole, and (b) C2-deuterated ( $\sim 95 \%$ labelled) 1-methylindole.

Scheme 2. Proposed Ionic Mechanism for the Catalytic Cycle of the Silylation Reaction

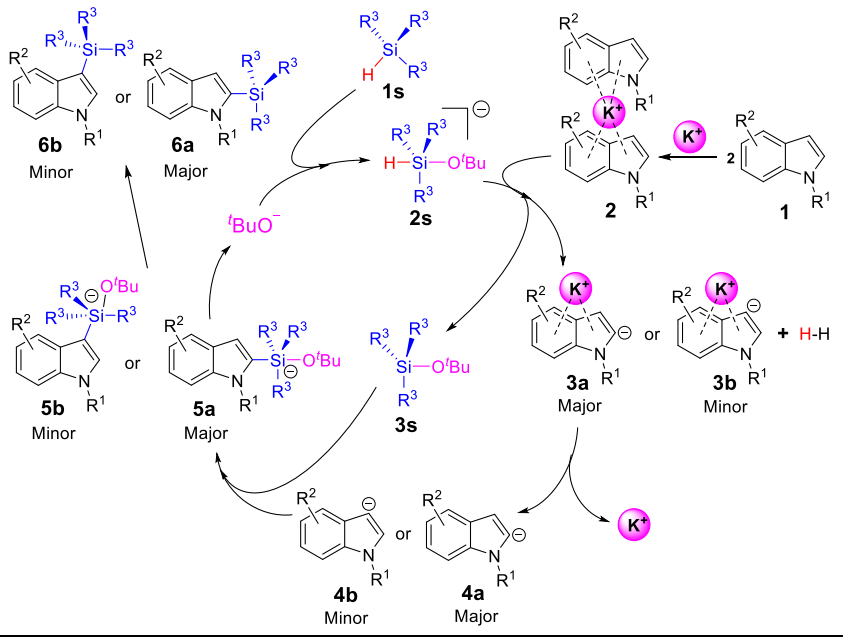

Likewise, a DESI-MS study of the silylation reaction of another type of substrate, i.e., dibenzofuran, ${ }^{9}$ intercepted deprotonated dibenzofuran species from the reaction mixture (Figure S3).

We also performed a time-dependent study on detecting the above anionic intermediates using DESI-MS after starting the reaction. The intermediates were detected only after $1 \mathrm{~h}$ of the reaction time, indicating that: (1) the reaction occurred in the bulk phase, not in DESI microdroplets, ${ }^{16,17}$ and (2) there is an induction period for the reaction to occur. The intermediates were transferred to gas phase from the condensed phase (reaction mixture) by the DESI soft ionization process.

An Ionic Mechanism. On the basis of the above observations, and considering all of the other reaction features originally reported by Toutov et al., ${ }^{9}$ Scheme 2 presents a plausible ionic mechanism for the silylation reaction. In the first step of the mechanism, the ' $\pi$-rich' heteroarene (1) interacts with $\mathrm{K}^{+}$to form a cation- $\pi$ complex 2 (detected, see later). Complexation makes the heteroarene protons $\mathrm{C} 2-\mathrm{H}$ and C3-H more acidic, facilitating deprotonation by a strong base. Although the most obvious base present in the reaction mixture is ${ }^{t} \mathrm{BuO}^{-}$, we propose that ${ }^{t} \mathrm{BuO}^{-}$does not directly deprotonate 2 but instead reacts with the silane $1 \mathrm{~s}$ to form a pentacoordinate silicon complex (2s) (see Supplementary Note 2 ) and that $2 \mathrm{~s}$ becomes a source of hydride ion to abstract the acidic proton from 2 . This proposed step resembles the formation of hydride ions by the reaction between metal alkoxide and hydrosilane reported earlier. ${ }^{18}$ However, from the present experimental data we cannot ascertain whether proton abstraction from the heteroarene substrate by the leaving hydride group of $2 \mathrm{~s}$ occurs in a concerted or a stepwise way. Deprotonation of $\mathbf{2}$ leads to the formation of ion pairs 3a (major) and $\mathbf{3 b}$ (minor), with hydrogen gas as a byproduct (detected, see Figure 3a).

Ion pair $\mathbf{3 a / 3} \mathbf{b}$ is proposed to dissociate to give the anions 4a/4b (deprotonated heteroarene) that were unambiguously detected in the DESI-MS experiment (Figure 1). These reactive, nucleophilic heteroarene carbanions $\mathbf{4 a / 4 b}$ are proposed to attack the silylether $\mathbf{3 s}$ to form pentacoordinate 
silicon intermediate $\mathbf{5 a / 5 b}$, which was also detected by DESIMS (Figure 1a). Subsequent dissociation of ${ }^{t} \mathrm{BuO}^{-}$from $\mathbf{5 a} / \mathbf{5} \mathbf{b}$ leads to the products $\mathbf{6 a} / \mathbf{6 b}$, which can form a cation- $\pi$ complex with $\mathrm{K}^{+}$(Figure S2).
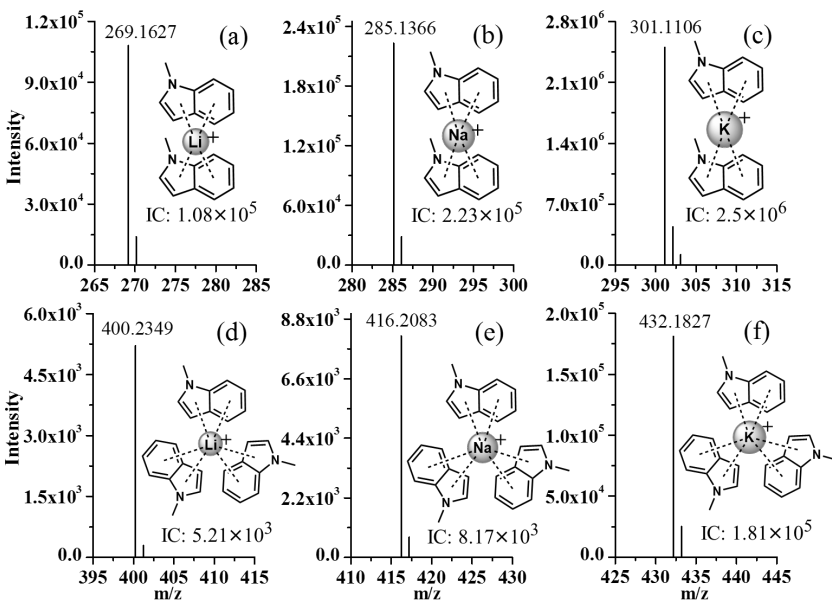

Figure 2. ESI mass spectra indicating the cation- $\pi$ interactions involving $\mathrm{Li}+/ \mathrm{Na}+/ \mathrm{K}+$ and 1-methylindole. A methanolic solution of $1 \mathrm{mM} 1$-methylindole (MI) containing lithium acetate, sodium acetate and potassium acetate, each at concentration of $10 \mathrm{mM}$, was electrosprayed in positive ion mode and the corresponding mass spectrum recorded the ion signals of different cation- $\pi$ complexes: (a) $[2 \mathrm{MI}+\mathrm{Li}]+\mathrm{m} / \mathrm{z} 269.1627$, (b) $[2 \mathrm{MI}+\mathrm{Na}]+\mathrm{m} / \mathrm{z}$ 285.1366 , (c) $[2 \mathrm{MI}+\mathrm{K}]+\mathrm{m} / \mathrm{z}$ 301.1106, (d) $[3 \mathrm{MI}+\mathrm{Li}]+\mathrm{m} / \mathrm{z}$ 400.2349 , (e) $[3 \mathrm{MI}+\mathrm{Na}]+\mathrm{m} / \mathrm{z} 416.2083$, (f) $[3 \mathrm{MI}+\mathrm{K}]+\mathrm{m} / \mathrm{z}$ 432.1827. Strengths of these cation- $\pi$ interactions are also represented by the values of their ion currents (IC).

Evidence for Cation- $\boldsymbol{\pi}$ Complex Formation. As 3a and 3b are neutral, mass spectrometry cannot detect them. However, the precursor cation- $\pi$ complex 2 was detected by ESI-MS (see below), and the proposed deprotonation of $\mathbf{2}$ leading to ion pairs $\mathbf{3 a}$ and $\mathbf{3 b}$ is supported by the observation that indole substrates possessing electron withdrawing groups $\left(-\mathrm{NO}_{2},-\mathrm{CN}\right.$, etc. $)$ were unreactive to catalysis. ${ }^{9}$ The $\pi$-electron deficiency of these heteroarenes would inhibit the formation of cation- $\pi$ complex 2 . As expected, we did not observe any deprotonated species from these heteroarenes $\left(\mathrm{Ar}-\mathrm{NO}_{2}, \mathrm{Ar}-\right.$ $\mathrm{CN}$, etc.) when the corresponding reaction mixtures were studied by DESI-MS.

Further support for the reaction route from $\mathbf{1}$ to $\mathbf{2}$ to $\mathbf{3 a} / \mathbf{3 b}$ comes from electrospray ionization mass spectrometry (ESIMS). ${ }^{19}$ When we electrosprayed a methanolic solution of 1methylindole (MI) containing $\mathrm{Li}^{+}, \mathrm{Na}^{+}$, and $\mathrm{K}^{+}$ions in an equimolar ratio, we detected the formation of cation- $\pi$ complexes (Figure 2). Although we did not detect the ion signal of $[\mathrm{MI}+\mathrm{M}]^{+}$, we detected the ion signal of $[2 \mathrm{MI}+\mathrm{M}]^{+}$ corresponding to cation- $\pi$ sandwich complexes ${ }^{20}$ (e.g., 2) (Figures $2 \mathrm{a}-\mathrm{c}$ ) and the ion signal of $[3 \mathrm{MI}+\mathrm{M}]^{+}$corresponding to the interaction of the central metal ion with three heteroarene molecules ${ }^{21}$ (Figures 2d-f). Interestingly, for both types of complex, the ion signal (ion current: IC) intensities followed the order: $\mathrm{K}^{+}$-complex $>\mathrm{Na}^{+}$-complex $>\mathrm{Li}^{+}$-complex even though the cation- $\pi$ interaction strengths are expected to follow the reverse order in the gas phase. ${ }^{21}$ The trade-off between solvation and cation- $\pi$ interaction modifies the strength of the cation- $\pi$ interaction in solution $\left(\mathrm{K}^{+}\right.$-complex $>$ $\mathrm{Na}^{+}$-complex $>\mathrm{Li}^{+}$-complex $)^{22}$ and hence results in the highest signal intensity for the $\mathrm{K}^{+}$-complex and the lowest signal intensity for the $\mathrm{Li}^{+}$-complex. Earlier studies also support the proposal that $\mathrm{K}^{+}$forms stronger cation- $\pi$ interactions with arenes in solution than does $\mathrm{Na}^{+}$or $\mathrm{Li}^{+} \cdot{ }^{22-24}$ These findings on the relative strengths of the cation- $\pi$ interactions suggest one possible explanation for the ineffectiveness of $\mathrm{NaO}^{t} \mathrm{Bu}$ and $\mathrm{LiO}^{t} \mathrm{Bu}$ as catalysts for the dehydrogenative $\mathrm{C}-\mathrm{H}$ silylation.

Nuclear magnetic resonance (NMR) spectroscopy provided further evidence for cation- $\pi$ complex formation. We recorded the ${ }^{1} \mathrm{H}$ NMR spectra (Figure S4) of methanolic $\left(\mathrm{CD}_{3} \mathrm{OD}\right)$ solutions of 1-methylindole containing $\mathrm{Li}^{+}$or $\mathrm{Na}^{+}$or $\mathrm{K}^{+}$. The chemical shifts of the aromatic protons differed for different salt solutions. Downfield peak shifting was observed, the magnitude of which followed the order: $\mathrm{K}^{+}$-solution $>\mathrm{Na}^{+}-$ solution $>\mathrm{Li}^{+}$-solution. This result once again indicates that $\mathrm{K}^{+}$possesses a higher affinity for 1 -methylindole in solution than does $\mathrm{Na}^{+}$or $\mathrm{Li}^{+}$.

When the silylation reaction was attempted using $\mathrm{LiO}^{t} \mathrm{Bu}$ or $\mathrm{NaO}^{t} \mathrm{Bu}$ as catalyst, no product was detected, even when the reaction was run for 5 days. ${ }^{9}$ We detected no ion signal of deprotonated 1-methylindole in a DESI-MS experiment when the reaction was run using $\mathrm{LiO}^{t} \mathrm{Bu}$ or $\mathrm{NaO}^{t} \mathrm{Bu}$ (Figure $\mathrm{S} 1$ ). The lack of reactivity of $\mathrm{LiO}^{t} \mathrm{Bu}$ or $\mathrm{NaO}^{t} \mathrm{Bu}$ might be attributed to the looser cation- $\pi$ interactions of $\mathrm{Li}^{+}$or $\mathrm{Na}^{+}$with 1methylindole, which may limit dissociation of the metal alkoxide and/or activation of the heteroarene. Another relevant observation in the original report was that addition of 18crown- 6 to the reaction mixture decelerated the reaction. ${ }^{9}$ Trapping of $\mathrm{K}^{+}$as the 18-crown-6 complex ${ }^{25}$ (detected in a DESI-MS experiment; see Figure S5) decreases the availability of the $\mathrm{K}^{+}$ion for pairing with the heteroarene (1) to form the intermediate cation- $\pi$ complex (2). All these observations collectively support the important role $\mathrm{K}^{+}$may play in driving the reaction through the formation of intermediates $\mathbf{2}$ and $\mathbf{3 a} / \mathbf{3 b}$.

Formation of the Hydride Donor to Deprotonate the Heteroarene. Silicon is less electronegative than hydrogen, and the $\mathrm{Si}-\mathrm{H}$ bond in 1 s possesses some hydridic character. ${ }^{26}$ Upon nucleophilic $\left({ }^{t} \mathrm{BuO}^{-}\right)$attack, the $\mathrm{Si}-\mathrm{H}$ bond in the pentacoordinate silicon intermediate $2 \mathrm{~s}$ can serve as a hydride donor (Supplementary Note 2). ${ }^{27-30}$ Indeed, cleavage of the $\mathrm{Si}-$ $\mathrm{H}$ bond in hydrosilanes by strong nucleophiles to form alkylated or arylated silanes with loss of hydride is precedented in the literature. ${ }^{31,32}$ Therefore, the silane hydrogen in $\mathbf{2 s}$ is expected to be sufficiently basic to abstract a proton from 2 leading to formation of $\mathrm{H}_{2}$ (detected, see Figure 3a). This proposition is further supported by an isotope labelling experiment: when we used C2-deuterated 1methylindole substrate (1) in the silylation reaction, we observed the evolution of HD gas (Figure S6).

When different alkoxide bases were used as catalysts in stoichiometric reactions, the reaction efficiencies followed roughly the basicities (i.e., $\mathrm{KO}^{t} \mathrm{Bu}>\mathrm{KOEt}>\mathrm{KOMe}$ ). ${ }^{2}$ This behavior is consistent with the proposed addition of the alkoxide anion to the silane (1s) to form the reactive pentacoordinate silicon intermediate (e.g., 2s). 

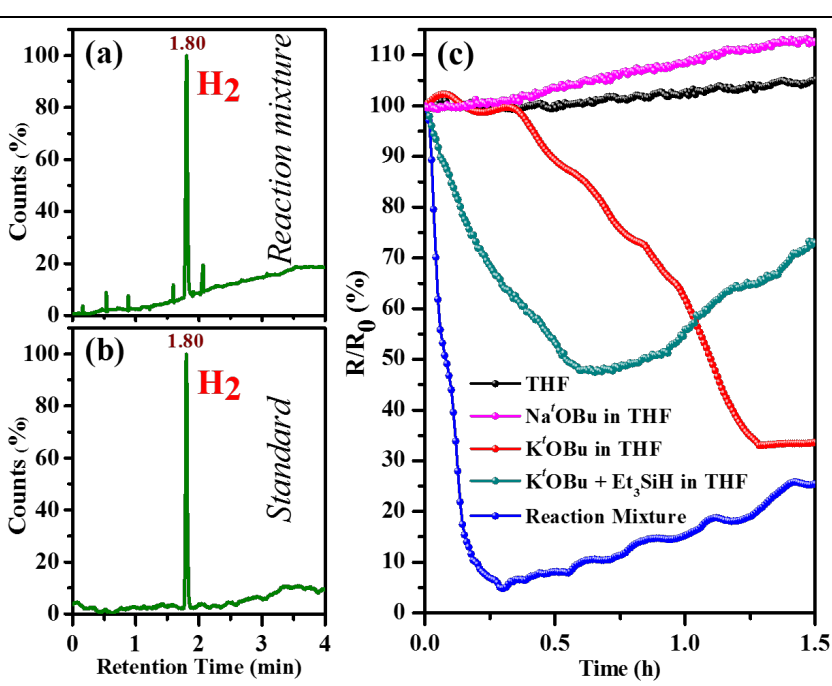

Figure 3. The left panels show the gas chromatographic detection of hydrogen gas from (a) the reaction mixture, and (b) the standard sample. The chromatographic signal intensities (counts) were normalized to 100 . The right panel (c) shows the assessment of electrolytic properties of the catalyst, reagents, and the silylation reaction mixture (mixture of 1-methylindole, $\mathrm{KO}^{t} \mathrm{Bu}$, and $\mathrm{Et}_{3} \mathrm{SiH}$ in THF) by measuring the resistance (R) over time at $45{ }^{\circ} \mathrm{C}$. $\mathrm{R}$ is normalized, showing the relative change of $\mathrm{R}$ in percentage over time. See Experimental Section for details.

Conductivity Studies. $\mathrm{KO}^{t} \mathrm{Bu}$ in THF is reported to have a neutral tetrameric cubane-like structure. ${ }^{33}$ DFT calculations in continuum solvent predict that it requires $36 \mathrm{kcal} / \mathrm{mol}$ to dissociate $\left(\mathrm{KO}^{t} \mathrm{Bu}\right)_{4}$ into ions (Figure $\mathrm{S} 7$ ), although this is likely a high estimate, as specific $\mathrm{K}^{+}-\mathrm{THF}$ interactions would stabilize the ions. In line with this theoretical result, a conductivity study shows that $\mathrm{KO}^{t} \mathrm{Bu}$ is indeed a poor electrolyte in THF (Figure 3c). However, unlike $\mathrm{NaO}^{t} \mathrm{Bu}$, $\mathrm{KO}^{t} \mathrm{Bu}$ was found to dissociate gradually to some extent over time until it reached an equilibrium point $(\sim 1.3 \mathrm{~h}$ in Figure $3 \mathrm{c})$ after which no further dissociation occurred. Conductimetric analysis of a silylation reaction mixture (1-methylindole, $\mathrm{KO}^{t} \mathrm{Bu}, \mathrm{Et}_{3} \mathrm{SiH}$ in $\mathrm{THF}$ ) showed a steep fall in resistance within 18 minutes after starting the reaction, suggesting a steep increase in solution conductance, which is an indication of increased abundance of ions $\left[\right.$ e.g., $\mathrm{K}^{+},{ }^{t} \mathrm{BuO}^{-}$or $\mathbf{2}$, and $\left.\mathrm{Et}_{3}\left({ }^{t} \mathrm{BuO}\right) \mathrm{SiH}^{-}(2 \mathbf{s})\right]$ in the solution during this time. The cation- $\pi$ interaction shown in $\mathbf{2}$ is likely to facilitate the dissociation of $\mathrm{KO}^{t} \mathrm{Bu}$. Dissociation simultaneously produces the ${ }^{t} \mathrm{BuO}^{-}$needed to form the hydride donor $2 \mathbf{s}$. Once the reaction of $\mathbf{2}$ with $2 \mathbf{s}$ starts, the ion availability is expected to decrease because of the formation of neutral ion pair $\mathbf{3 a} / \mathbf{3} \mathbf{b}$ and silylether 3s. This behavior is consistent with the gradual increase in resistance after 18 minutes of the reaction (Figure $3 \mathrm{c})$. This conductivity study is consistent with the observation that the reaction has an induction period before product formation commences, as detected by mass spectrometry, and also provides a possible explanation for why $\mathrm{NaO}^{t} \mathrm{Bu}$ does not succeed as a catalyst. ${ }^{9}$

NMR and EPR studies. This reaction was also studied by NMR. We failed to observe any intermediate signals relevant to either ionic or radical mechanisms, indicating that the concentrations of intermediates were too small to be detected. We also performed EPR studies (Figure S11), and we did detect a silyl radical species (vide infra) but not any type of indole radical intermediates. Mass spectrometry is a more highly sensitive technique than NMR or EPR spectroscopy, and has an established role in detecting transient ionic intermediates. ${ }^{34-36}$

Reactions of Different Heteroarenes. When the silylation reaction was performed in a competition experiment ${ }^{9}$ involving different heteroarenes, such as a sulfur-containing heteroarene (thiophene), oxygen-containing heteroarene (furan), and nitrogen-containing heteroarene (1methylpyrrole), the reactivity order was found to be: thiophene $>$ furan $>1$-methylpyrrole, which corresponds to the order of acidity of these heteroarenes $\left(\mathrm{pK}_{\mathrm{a}}\right.$ of $\mathrm{C} 2-\mathrm{H}$ proton is $\sim 33$ for thiophene, $\sim 36$ for furan, and $\sim 40$ for 1-methylpyrrole in THF) ${ }^{14}$ These results are consistent with the deprotonation of the heteroarene being the rate-determining step of the catalytic cycle, which is also supported by DFT calculations (see later).

When the silylation reaction was carried out on electrondeficient heteroarenes such as pyridine, quinoline, isoquinoline, and acridine, no reaction or $<5 \%$ product was observed. ${ }^{9}$ This observation can also be explained by the ionic mechanism, if deprotonation is rate-limiting. First, the $\mathrm{pK}_{\mathrm{a}}$ values for all the $\mathrm{C}-\mathrm{H}$ bonds in these substrates are very high (average $\mathrm{pK}_{\mathrm{a}}$ greater than 40 in THF) and these substrates are much less susceptible to deprotonation by the base. ${ }^{14}$ Second, the electron-deficient nature of these heterocycles decreases the likelihood of the cation- $\pi$ interaction. Third, the localized lone pair on the heterocyclic nitrogen has a tendency to complex with potassium, ${ }^{37}$ further weakening any cation- $\pi$ interactions.

The nature of alkyl/aryl substituents in the heteroarene and silane $\left(R^{1}, R^{2}\right.$, and $R^{3}$; Schemes 1 and 2) affect the yield in a manner consistent with the proposed catalytic cycle. ${ }^{9}$ With increasing $+\mathrm{I}$ and/or $+\mathrm{R}$ effect $^{38}$ of the alkyl/aryl substituents attached to the heteroarene $\mathbf{1}\left(\mathrm{R}^{1}\right.$ and $\left.\mathrm{R}^{2}\right)$, the reaction rate and yield were lower, ${ }^{9}$ consistent with the lower acidity of $\mathbf{2}$. In contrast, with increasing $+\mathrm{I}$ effect of alkyl substituents $\left(\mathrm{R}^{3}\right)$ on the hydrosilane (1s), the reaction efficiency was found to increase, ${ }^{9}$ consistent with more facile hydride elimination from 2s. These substituent effects are further evidence for ratedetermining deprotonation.

DFT Calculations. We computed the free energy profile of the ionic mechanism with DFT. Figure 4 summarizes the results from calculations performed with M06-2X/6$311+\mathrm{G}(\mathrm{d}, \mathrm{p})-\mathrm{CPCM}(\mathrm{THF}) / / \mathrm{B} 3 \mathrm{LYP} / 6-31 \mathrm{G}(\mathrm{d})$ on the reaction of ${ }^{t} \mathrm{BuO}^{-}$with 1-methylindole and a model silane, $\mathrm{Me}_{3} \mathrm{SiH}$, in THF. After formation of the pentacoordinate intermediate Inta (analogous to 2s), dissociation of the $\mathrm{Si}-\mathrm{H}$ bond gives $\mathrm{H}^{-}$and ${ }^{t} \mathrm{BuOSiMe}_{3}$. The hydride ion then deprotonates 1methylindole, via transition state TSa, generating 2-indolyl anion 4a plus $\mathrm{H}_{2}$. The deprotonation is regioselective: $\mathrm{C} 2$ deprotonation is favored by $3.8 \mathrm{kcal} / \mathrm{mol}$ relative to $\mathrm{C} 3$ deprotonation (via TSa_C3, Figure S8). Next, nucleophilic addition of 2-indolyl anion $\mathbf{4 a}$ to ${ }^{t} \mathrm{BuOSiMe}_{3}$ via TSb leads to pentacoordinate intermediate Intc (analogous to 5a). Finally, dissociation of ${ }^{t} \mathrm{BuO}^{-}$via TSc gives the silylated heteroarene product.

The calculations predict that the deprotonation of the heteroarene is the rate-limiting step of the ionic mechanism, consistent with the experimental results discussed above. The computed barrier $\left(\Delta G^{\ddagger}\right)$ relative to $\mathrm{Me}_{3} \mathrm{SiH},{ }^{t} \mathrm{BuO}^{-}$, and 1methylindole is $15.1 \mathrm{kcal} / \mathrm{mol}$. This barrier would be easily surmountable at the temperatures typically used for the 
silylation reaction $\left(25-65{ }^{\circ} \mathrm{C}\right)$, which suggests that the formation of the cation- $\pi$ complex between 1-methylindole and $\mathrm{K}^{+}$is not strictly essential for deprotonation to occur (although it would make the heteroarene more acidic). The major role of cation- $\pi$ complex formation in this mechanism is to promote the dissociation of the $\mathrm{KO}^{t} \mathrm{Bu}$ tetramer into $\mathrm{K}^{+}$and ${ }^{t} \mathrm{BuO}^{-}$ions.

A Complementary Neutral Heterolytic Mechanism. The above calculations predict that the ionic mechanism described in Scheme 2 is facile, provided that $\mathrm{H}^{-}$can be readily generated in the reaction mixture. The DESI-MS analyses (Figure 1) and conductivity experiments (Figure 3c) indicate that $\mathrm{KO}^{t} \mathrm{Bu}$ dissociates, at least partially, into ions under the reaction conditions. We also considered an alternative mechanism that does not require dissociation of the tetramer (Figure 5). This mechanism is broadly analogous to the ionic pathway, but the intermediates are neutral. First, a $\mathrm{Si}-\mathrm{O}$ bond is formed between $\mathrm{Me}_{3} \mathrm{SiH}$ and the $\mathrm{KO}^{t} \mathrm{Bu}$ tetramer via transition state TSd, giving pentacoordinate intermediate Intd. $\mathrm{Next}$, the $\mathrm{Si}-\mathrm{H}$ bond of Intd undergoes heterolysis (TSe). Rather than liberating a free $\mathrm{H}^{-}$ion, this step leads to hydride complex Inte, in which $\mathrm{H}^{-}$occupies one corner of the $\mathrm{K}_{4} \mathrm{X}_{4}$ unit and ${ }^{t} \mathrm{BuOSiMe}_{3}$ is coordinated to potassium. The coordinated hydride then deprotonates 1-methylindole, via TSf, leading to carbanion complex Intf and $\mathrm{H}_{2}$. Intramolecular Si-C bond formation (TSg), followed by pseudorotation (TSh) and finally dissociation of ${ }^{t} \mathrm{BuO}^{-}$(TSi), gives the silylated heteroarene product.

Like the ionic mechanism, the rate-determining step of the neutral heterolytic (tetrameric) mechanism is the deprotonation of the heteroarene (TSf). The overall barrier relative to $\mathrm{Me}_{3} \mathrm{SiH}, \mathrm{KO}^{t} \mathrm{Bu}$, and 1-methylindole is 28.3 $\mathrm{kcal} / \mathrm{mol}$. Deprotonation of 1-methylindole is regioselective; the barrier for $\mathrm{C} 2$ deprotonation is $5.0 \mathrm{kcal} / \mathrm{mol}$ lower than that for C3 deprotonation (see the Supporting Information). The neutral mechanism is driven by the dipolar effects mediated by the tetrameric $\mathrm{K}_{4}$ cluster. In the initial stage of the reaction, the pentacoordinate silicon intermediate Intd is stabilized by interaction of the silane hydrogen with the nearby potassium ion. In carbanion complex Intf, and subsequent intermediates in the catalytic cycle, the heteroarene engages in a cation- $\pi$ interaction with potassium. Although the computed barrier of the neutral mechanism $(28.3 \mathrm{kcal} / \mathrm{mol})$ is significantly higher than the barrier for the ionic mechanism shown in Figure 4 $(15.1 \mathrm{kcal} / \mathrm{mol})$, this does not necessarily mean that the ionic mechanism (Figure 4) is favored over the neutral mechanism (Figure 5). These barriers are calculated with respect to different sets of reactants and the calculations in Figure 4 do not include the initial dissociation of the $\mathrm{KO}^{t} \mathrm{Bu}$ tetramer into ions.

The tetrameric mechanism, with a rate-determining deprotonation step, provides alternative explanations for the important features of the silylation chemistry discussed above. For example, the inability of $\mathrm{NaO}^{t} \mathrm{Bu}$ to catalyze the silylation can be explained by the observation that the transition state for deprotonation of 1-methylindole (analogous to TSf) in a reaction catalyzed by $\mathrm{NaO}^{t} \mathrm{Bu}$ has a barrier of $38.9 \mathrm{kcal} / \mathrm{mol}$, more than $10 \mathrm{kcal} / \mathrm{mol}$ higher than the barrier for TSf in the $\mathrm{KO}^{t} \mathrm{Bu}$-catalyzed silylation. This barrier is too high for the reaction to occur under the typical experimental conditions, and reflects the weaker basicity of the more tightly bound hydride in the sodium analogue of Inte. Also, the computed barriers for deprotonation of other heteroarenes (thiophene, furan, and 1-methylpyrrole) with $\mathrm{KO}^{t} \mathrm{Bu}$ as the catalyst predict the correct order of reactivities measured experimentally. ${ }^{9}$ Thirdly, the barriers for deprotonation of electron-deficient substrates pyridine and $\mathrm{PhCN}$ (which failed to undergo the silylation $^{9}$ ) are calculated to be $2-4 \mathrm{kcal} / \mathrm{mol}$ higher than the barrier for deprotonation of 1-methylindole. Indeed, it is easier for these two electron-deficient substrates to form a $\mathrm{C}-\mathrm{O}$ bond with the $\mathrm{KO}^{t} \mathrm{Bu}$ tetramer ${ }^{39}$ than to undergo deprotonation (see Supplementary Note 3 ).

Finally, in the original 2015 paper, ${ }^{9}$ it was reported that the reaction was inhibited by $20 \mathrm{~mol} \%$ TEMPO. We believe that this inhibition can be readily explained as outlined in Scheme 3. H-abstraction by TEMPO from the catalytic intermediate Inte has a very low activation energy (DFT calculations give a $\Delta G^{\ddagger}=16.4 \mathrm{kcal} / \mathrm{mol}$ ) giving Intk and TEMPO-H. This effectively removes Inte (the key base required for the deprotonation of the heteroarene) from the reaction mixture. Radical Intk would be expected to be trapped by TEMPO at close to diffusion-controlled rates to give a stable adduct 7 .

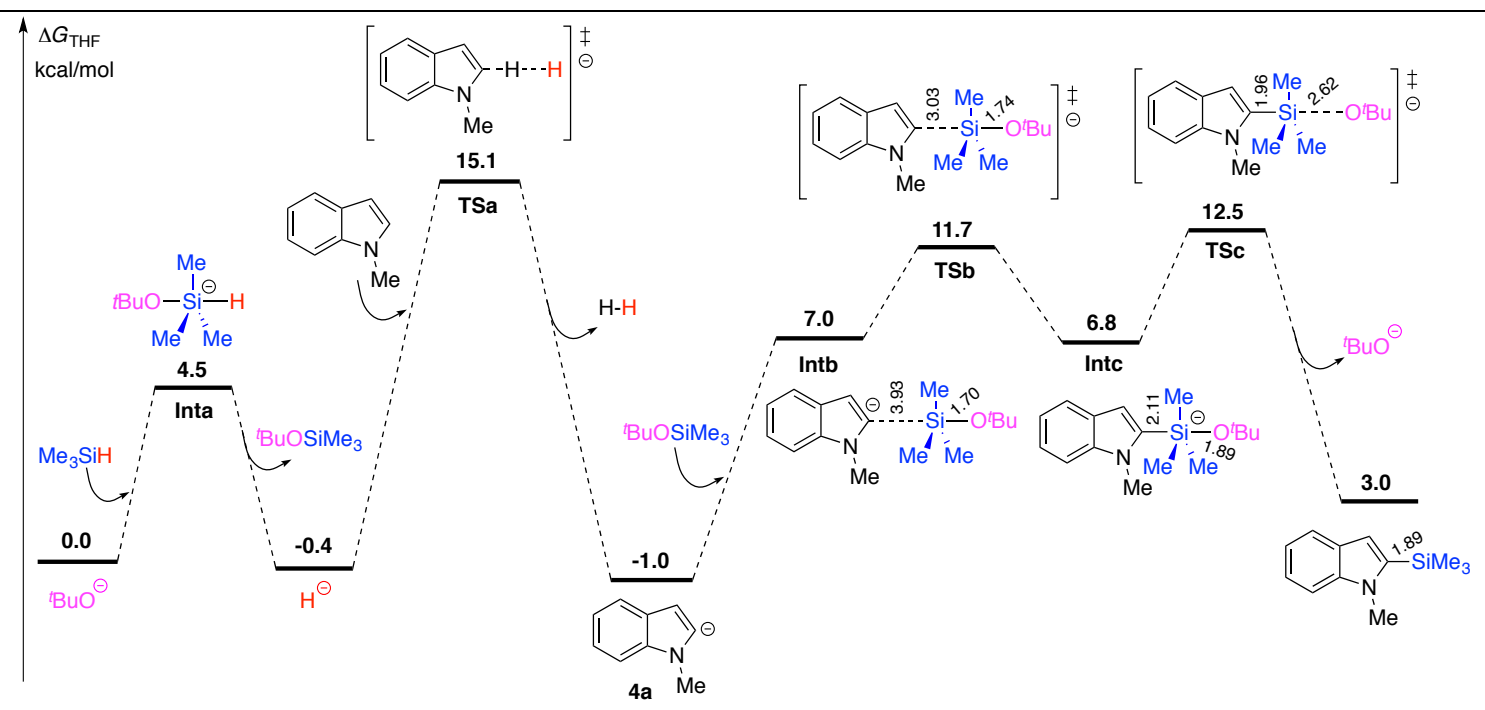


Figure 4. Free energy diagram of the ionic mechanism for $\mathrm{KO}^{t} \mathrm{Bu}$-catalyzed silylation of 1-methylindole (energy required to dissociate $\mathrm{KO}^{t} \mathrm{Bu}$ into ions not included). See SI for details.

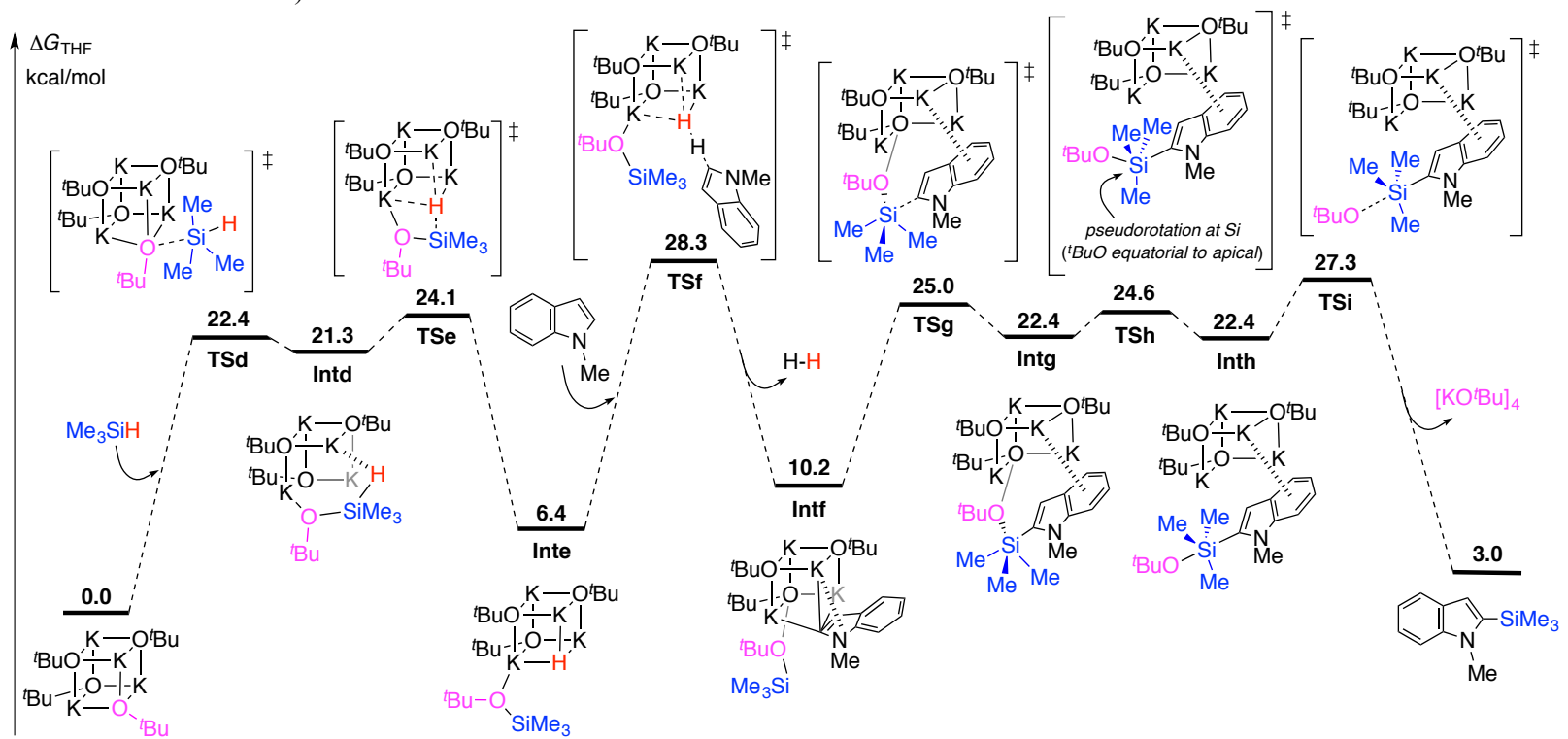

Figure 5. Free energy diagram of the neutral heterolytic mechanism for $\mathrm{KO}^{t} \mathrm{Bu}$-catalyzed silylation of 1-methylindole.

Scheme 3. Inhibition of the Silylation Reaction by TEMPO

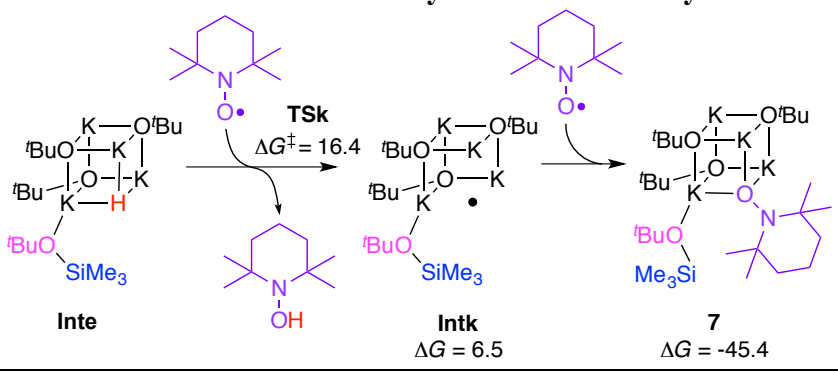

As Inte (Scheme 3 ) is a reasonably good $\mathrm{H}$ atom donor, the presence of a trace of oxygen in the reaction mixture could also promote the formation of an intermediate $\mathrm{HO}_{2}$ complex by the donation of $\mathrm{H}$ atom from Inte to $\mathrm{O}_{2}$ (Figure $\mathrm{S} 10$ ). The resulting $\mathrm{HO}_{2}$ complex could then undergo $\mathrm{O}-\mathrm{O}$ homolysis giving $\mathrm{OH}$ and a coordinated oxyl radical. These radical species could presumably then abstract $H$ from the silane to generate silyl radicals (detected in our EPR study, Figure S11). The overall barrier for the formation of $\mathrm{OH}$ and coordinated oxyl radicals by this pathway is $24.7 \mathrm{kcal} / \mathrm{mol}$ (Figure S10). Detailed studies of radical pathways for the $\mathrm{KO}^{t} \mathrm{Bu}$-catalyzed silylation reaction are presented separately in the accompanying paper.

\section{CONCLUSION}

In summary, we suggest two plausible mechanisms-one ionic, the other a neutral heterolytic mechanism-for the $\mathrm{KO}^{t} \mathrm{Bu}$ catalyzed $\mathrm{C}-\mathrm{H}$ silylation of heteroarenes, based on a combination of empirical evidence and DFT calculations. The two mechanisms are closely related, featuring cation- $\pi$ interactions, preferential abstraction of the $\mathrm{C} 2$-proton from the indole, and formation of pentacoordinate silicon species, all of which were observed experimentally. The key steps are nucleophilic attack of $\mathrm{KO}^{t} \mathrm{Bu}$ on the silane to form a reactive pentacoordinate silicon species, followed by rate-limiting $\mathrm{Si}-$
$\mathrm{H}$ heterolysis, deprotonation of the heteroarene substrate, addition of the heteroarene carbanion to the silylether intermediate, and eventually the release of ${ }^{t} \mathrm{BuO}^{-}$to give the silylated heteroarene product.

The computed activation barriers for both mechanisms (Figures 4 and 5) are consistent with the observed reaction time for silylation of 1-methylindole under the conditions of the synthesis $\left(48-61 \mathrm{~h}, 45^{\circ} \mathrm{C}\right) .{ }^{9}$ It is possible that both the ionic mechanism and the neutral heterolytic mechanism are operative along with other unknown mechanism(s). The ionic species detected by the DESI-MS and conductivity measurements are key intermediates in the ionic mechanism (Figure 4), but they are not essential in the neutral mechanism (Figure 5). Here, they could simply be "spectator" ions, formed by partial dissociation of the neutral intermediates. Dissociation of the 2-indolyl anion 4a from Intf is computed to require $16.1 \mathrm{kcal} / \mathrm{mol}(\Delta G)$, while the energy of dissociation of (2-indolyl) $\mathrm{SiMe}_{3}\left(\mathrm{O}^{t} \mathrm{Bu}\right)^{-}$(analogous to 5a) from Inth is 7.8 $\mathrm{kcal} / \mathrm{mol}$. It should be noted that the neutral intermediates involved in the neutral heterolytic mechanism (Figure 5) could also be fragmented inside the charged microdroplet resulting in gas-phase ions, which were detected in the DESI-MS experiment (Figure 1). Analyte fragmentation or transformation in charged microdroplets is known to be possible. ${ }^{16,40,41}$ It should also be noted that the silylation reaction also proceeds with other bases (catalysts) like KOEt, KHDMS, or KOTMS, ${ }^{9}$ which are less likely to follow the tetrameric mechanism (Figure 5), and more likely to follow the ionic mechanism similar to Scheme 2. Recently, charged microdroplets have been demonstrated to accelerate reactions. $^{16,42}$ It is therefore quite possible that some differences occur, perhaps even very important ones, in looking at the same reaction in bulk solution. ${ }^{43}$ Nonetheless, the ionic and heterolytic mechanisms are consistent with the combined results of the DESI-MS, NMR, and conductivity experiments, and can successfully explain the observed 
reactivities and selectivities of different heteroarenes and catalysts in the silylation process.

\section{EXPERIMENTAL SECTION}

Materials. All the necessary chemicals were purchased from Sigma-Aldrich (St. Louis, MO). The deuterated 1methylindole was prepared according to the literature procedure. ${ }^{44}$ HPLC grade solvents were purchased from Fisher Scientific (Nepean, ON, Canada).

Silylation reaction ${ }^{9}$ for mass spectrometric study. In a nitrogen-filled glove box, $0.1 \mathrm{mmol}(\sim 13 \mu \mathrm{L})$ 1-methylindole and $0.05 \mathrm{mmol}(20 \mathrm{~mol} \%, 2.5 \mathrm{mg}) \mathrm{KO}^{t} \mathrm{Bu}$ were added to 100 $\mu \mathrm{L}$ dry tetrahydrofuran (THF) taken in a 2 dram scintillation vial equipped with a magnetic stirring bar, followed by the addition of $0.3 \mathrm{mmol}(\sim 50 \mu \mathrm{L})$ triethylsilane (by filtering through a short pad of activated alumina before use). The vial was then sealed and the mixture was stirred at $30{ }^{\circ} \mathrm{C}$. After $2 \mathrm{~h}$ of the reaction, $20 \mu \mathrm{L}$ reaction aliquot was pipetted out and dispensed immediately onto the DESI spray spot (on a glass plate, solvent: $1: 1 \mathrm{v} / \mathrm{v} \mathrm{ACN}$ and DMF) created at around $2 \mathrm{~mm}$ away from the heated capillary inlet of the mass spectrometer (see Figure S1).

Desorption electrospray ionization mass spectrometry. The DESI-MS studies ${ }^{13}$ were performed on a high-resolution mass spectrometer (Thermo Scientific LTQ Orbitrap XL Hybrid Ion Trap-Orbitrap mass spectrometer) using a homebuilt DESI source. The source was constructed by using an inner fused silica capillary $(100 \mu \mathrm{m}$ i.d. and $360 \mu \mathrm{m}$ o.d.) for solvent delivery, and an outer (coaxial) stainless steel capillary $(0.5$ $\mathrm{mm}$ i.d. and $1.6 \mathrm{~mm}$ o.d.) for nebulizing gas (nitrogen) delivery as shown in Figure S1. A stream of charged microdroplets, produced from this DESI source at ambient temperature and atmospheric pressure, was directed to the analyte surface (on a glass plate) at an incident angle $\sim 55^{\circ}$ with the spray tip-to-surface distance of $\sim 5 \mathrm{~mm}$, spray tip-tomass spectrometric inlet distance of $\sim 10 \mathrm{~mm}$, and collection angle of $\sim 5^{\circ}$. The charged droplets were produced either in negative ion mode $(-5 \mathrm{kV}$ spray voltage) or at positive ion mode (+5 $\mathrm{kV}$ spray voltage), at $10 \mu \mathrm{L} / \mathrm{min}$ solvent $(1: 1 \mathrm{v} / \mathrm{v}$ $\mathrm{ACN}$ and DMF) flow through silica tubing with the coaxial nebulizing gas flow $\left(\mathrm{N}_{2}\right.$ at $\left.120 \mathrm{psi}\right)$. The splashing of these charged microdroplets on the analyte surface resulted in the formation of secondary microdroplets encapsulating the analyte molecules (ions), which were then transferred to the mass spectrometer through a heated capillary causing the complete desolvation of the analyte ions. The heated capillary (MS inlet) temperature and voltage were maintained at $275^{\circ} \mathrm{C}$ and $44 \mathrm{~V}$ respectively. All experiments were carried out under identical conditions, unless otherwise stated. The ion optics were tuned to get maximum ion count. Data acquisition was performed for 1 min using XCalibur software (Thermo Fisher Scientific)

Electrospray ionization mass spectrometry. ESI-MS studies ${ }^{19,45}$ were performed on the same mass spectrometer as mentioned above with a homebuilt ESI source similar to the above DESI source. The analyte solution (in methanol) was injected to the ESI source (on-axis) at a flowrate $5 \mu \mathrm{L} / \mathrm{min}$ in positive ion mode $(+5 \mathrm{kV})$ with a coaxial sheath gas flow $\left(\mathrm{N}_{2}\right.$ at 120 psi). The mass spectrometer (MS) inlet capillary temperature was maintained at $275^{\circ} \mathrm{C}$, and capillary voltage was kept at $44 \mathrm{~V}$. The spray distance (the on-axis distance from spray tip to the entrance of the heated capillary) was kept at $1.5 \mathrm{~cm}$. All experiments were carried out under identical conditions. The ion optics were tuned to get maximum ion count. Data acquisition was performed for $1 \mathrm{~min}$ using XCalibur software (Thermo Fisher Scientific)

Gas chromatography. Hydrogen gas evolved from the reaction mixture was analyzed by gas chromatography (GC) on a carbon-based molecular sieve column (HP MOLSIV 30 $\mathrm{m} \times 0.320 \mathrm{~mm}$ ID, 12 micron) with thermal conductivity detection (TCD). A Hewlett-Packard 5890 GC with a splitsplitless injector was operated in the splitless mode for $0.5 \mathrm{~min}$ at which point the injector was purged with a split flow of 20 $\mathrm{mL} / \mathrm{min}$. Ultra-high purity nitrogen was used for carrier gas, and the column was operated at a constant flow rate of 2.2 $\mathrm{mL} / \mathrm{min}$ (37 cm/sec average linear velocity). Oven temperature was isothermal at $32{ }^{\circ} \mathrm{C}$. Injections of $50 \mu \mathrm{L}$ were performed manually with a gastight syringe. The injector was maintained at $150{ }^{\circ} \mathrm{C}$ and the detector at $200{ }^{\circ} \mathrm{C}$. Hydrogen eluted at approximately 2 minutes under these conditions. Absence of interference from other gases that were expected to be in any injection mixture was tested empirically.

Studying electrolytic properties of the reaction by sourcemeter. The electrolytic properties of the reaction system (mixture of $1 \mathrm{mmol} 1$-methylindole, $3 \mathrm{mmol}$ triethylsilane, and $0.2 \mathrm{mmol}$ potassium-t-butoxide in $1 \mathrm{~mL}$ anhydrous THF) and controls (anhydrous THF or $0.2 \mathrm{mmol}$ potassium- $t$-butoxide/sodium- $t$-butoxide in anhydrous THF or the reaction mixture without substrate) were assessed by a Keithley 2400 sourcemeter by measuring the resistance (R) of the above systems over time at $45{ }^{\circ} \mathrm{C}$. A constant current of $0.5 \mu \mathrm{A}$ was applied to the sourcemeter during the experiment using a four-wire setup (Cu-Sn electrodes) to measure the potential drop between the inner contacts, which was then converted to resistance value.

Computational details. All the calculations were carried out with Gaussian 09. ${ }^{46}$ Geometry optimizations were performed with the B3LYP method ${ }^{47-50}$ using the $6-31 G(d)$ basis set si-53 $^{51}$ for all atoms. Frequency analyses verified that the stationary points were minima or first-order saddle points. Single point energies were calculated at the M06-2X $\mathrm{X}^{54} / 6-311+\mathrm{G}(\mathrm{d}, \mathrm{p})$ level, with solvent effects (solvent $=$ THF) modeled using the $\mathrm{CPCM}^{55-57}$ solvation model. Gibbs free energies in THF at $298.15 \mathrm{~K}$ were calculated by adding the thermochemical quantities derived from the B3LYP frequencies to the M06-2X solution-phase electronic potential energy and then correcting the energy to a standard state of $1 \mathrm{~mol} / \mathrm{L}$. Computed structures are illustrated using CYLview. ${ }^{58}$

\section{ASSOCIATED CONTENT}

\section{Supporting Information}

Mass spectra, NMR spectra. DFT calculations. This material is available free of charge via the Internet at http://pubs.acs.org.

\section{AUTHOR INFORMATION}

\section{Corresponding Author}

*e.krenske@uq.edu.au

*houk@chem.ucla.edu

*zare@stanford.edu

\section{Author Contributions}

"These authors contributed equally to this work. 


\section{Notes}

The authors declare no competing financial interests.

\section{ACKNOWLEDGMENT}

Authors thank N. Dalleska (Caltech), R. Pfattner (Stanford), and M. R. Angell (Stanford) for their help. This work was supported by National Science Foundation under the CCI Center for Selective C-H Functionalization (CHE-1205646 and CHE-1361104), Air Force Office of Scientific Research through Basic Research Initiative grant (AFOSR FA9550-161-0113), and the Australian Research Council (FT120100632 to EHK). Calculations were performed on the Hoffman2 cluster at UCLA and the Extreme Science and Engineering Discovery Environment (XSEDE), which is supported by the NSF, and the National Facility of the Australian National Computational Infrastructure.

\section{REFERENCES}

(1) Armor, J. N. Catalysis Today 2011, 163, 3.

(2) Sun, C.-L.; Shi, Z.-J. Chemical Reviews 2014, 114, 9219.

(3) Yanagisawa, S.; Ueda, K.; Taniguchi, T.; Itami, K. Organic Letters 2008, 10, 4673 .

(4) Deng, G.; Ueda, K.; Yanagisawa, S.; Itami, K.; Li, C.-J. Chemistry - A European Journal 2009, 15, 333.

(5) Sun, C.-L.; Li, H.; Yu, D.-G.; Yu, M.; Zhou, X.; Lu, X.-Y.; Huang, K.; Zheng, S.-F.; Li, B.-J.; Shi, Z.-J. Nat Chem 2010, 2, 1044.

(6) Shirakawa, E.; Itoh, K.-i.; Higashino, T.; Hayashi, T. Journal of the American Chemical Society 2010, 132, 15537.

(7) Rueping, M.; Leiendecker, M.; Das, A.; Poisson, T.; Bui, L. Chemical Communications 2011, 47, 10629.

(8) Rathore, V.; Sattar, M.; Kumar, R.; Kumar, S. The Journal of Organic Chemistry 2016, 81, 9206 .

(9) Toutov, A. A.; Liu, W.-B.; Betz, K. N.; Fedorov, A.; Stoltz, B. M.; Grubbs, R. H. Nature 2015, 518, 80.

(10) Uematsu, R.; Maeda, S.; Taketsugu, T. Chemistry - An Asian Journal 2014, $9,305$.

(11) Schneider, N.; Finger, M.; Haferkemper, C.; Bellemin-Laponnaz, S.; Hofmann, P.; Gade, L. H. Chemistry - A European Journal 2009, 15, 11515 .

(12) Dubois, J.-E.; Boussu, M. Tetrahedron Letters 1970, 11, 2523.

(13) Takáts, Z.; Wiseman, J. M.; Gologan, B.; Cooks, R. G. Science 2004, 306,471 .

(14) Shen, K.; Fu, Y.; Li, J.-N.; Liu, L.; Guo, Q.-X. Tetrahedron 2007, 63, 1568 .

(15) Wouters, J. Protein Science 1998, 7, 2472.

(16) Banerjee, S.; Zare, R. N. Angewandte Chemie International Edition 2015, 54, 14795.

(17) Lee, J. K.; Banerjee, S.; Nam, H. G.; Zare, R. N. Quarterly Reviews of Biophysics 2015, 48, 437.

(18) Dolgov, B. N.; Kharitonov, N. P.; Voronkov, M. G. Zh. Obshch. Khim. 1954, 24, 1178.

(19) Banerjee, S.; Mazumdar, S. International Journal of Analytical Chemistry 2012, 2012, Article ID 282574.

(20) Wireduaah, S.; Parker, T. M.; Lewis, M. Journal of Physical Chemistry A 2013, 117, 2598.

(21) Dougherty, D. A. Accounts of Chemical Research 2013, 46, 885.

(22) Kumpf, R.; Dougherty, D. Science 1993, 261, 1708

(23) Zhu, D.; Herbert, B. E.; Schlautman, M. A.; Carraway, E. R. Journal of Environmental Quality 2004, 33, 276.
(24) Lu, Q.; Oh, D. X.; Lee, Y.; Jho, Y.; Hwang, D. S.; Zeng, H. Angewandte Chemie International Edition 2013, 52, 3944.

(25) Steed, J. W.; Atwood, J. L. Supramolecular Chemistry; Wiley, 2013. (26) Yang, L.; Hubbard, T. A.; Cockroft, S. L. Chemical Communications 2014, 50, 5212 .

(27) Mayr, H.; Basso, N.; Hagen, G. Journal of the American Chemical Society 1992, 114, 3060.

(28) Larson, G. L.; Fry, J. L. Ionic and Organometallic-Catalyzed Organosilane Reductions; Wiley, 2009.

(29) Schlosser, M. Organometallics in Synthesis, Third Manual; Wiley, 2013.

(30) Blackwell, J. M.; Sonmor, E. R.; Scoccitti, T.; Piers, W. E. Organic Letters 2000, 2, 3921.

(31) Meals, R. N. Journal of the American Chemical Society 1946, 68, 1880 .

(32) Chernyak, N.; Dudnik, A. S.; Huang, C.; Gevorgyan, V. Journal of the American Chemical Society 2010, 132, 8270.

(33) Chisholm, M. H.; Drake, S. R.; Naiini, A. A.; Streib, W. E.

Polyhedron 1991, 10, 337.

(34) Ingram, A. J.; Boeser, C. L.; Zare, R. N. Chemical Science 2016, 7, 39.

(35) Santos, L. S. Journal of the Brazilian Chemical Society 2011, 22, 1827 .

(36) Eberlin, M. European Journal of Mass Spectrometry, 13.

(37) Brown, D. J. The Chemistry of Heterocyclic Compounds, Pyridine Metal Complexes; Wiley, 2009.

(38) Smith, M. B.; March, J. March's Advanced Organic Chemistry: Reactions, Mechanisms, and Structure; Wiley, 2007.

(39) Barham, J. P.; Coulthard, G.; Emery, K. J.; Doni, E.; Cumine, F.; Nocera, G.; John, M. P.; Berlouis, L. E. A.; McGuire, T.; Tuttle, T.; Murphy, J. A. Journal of the American Chemical Society 2016, 138, 7402. (40) Banerjee, S.; Prakash, H.; Mazumdar, S. Journal of The American Society for Mass Spectrometry 2011, 22, 1707.

(41) Banerjee, S. Journal of Mass Spectrometry 2013, 48, 193.

(42) Lee, J. K.; Banerjee, S.; Nam, H. G.; Zare, R. N. Quart. Rev. Biophys. 2015, 48, 437 .

(43) Banerjee, S.; Gnanamani, E.; Yan, X.; Zare, R. N. Analyst 2017, DOI: $10.1039 / C 6 A N 02225 A$.

(44) Lane, B. S.; Brown, M. A.; Sames, D. Journal of the American Chemical Society 2005, 127, 8050.

(45) Fenn, J.; Mann, M.; Meng, C.; Wong, S.; Whitehouse, C. Science 1989, 246, 64 .

(46) Frisch, M.; Trucks, G.; Schlegel, H.; Scuseria, G.; Robb, M.; Cheeseman, J.; Scalmani, G.; Barone, V.; Mennucci, B.; Petersson, G. Inc., Wallingford, CT 2009.

(47) Lee, C.; Yang, W.; Parr, R. G. Physical Review B 1988, 37, 785.

(48) Becke, A. D. The Journal of Chemical Physics 1993, 98, 1372.

(49) Becke, A. D. The Journal of Chemical Physics 1993, 98, 5648. (50) Stephens, P. J.; Devlin, F. J.; Cheeseman, J. R.; Frisch, M. J. The Journal of Physical Chemistry A 2001, 105, 5356.

(51) Ditchfield, R.; Hehre, W. J.; Pople, J. A. The Journal of Chemical Physics 1971, 54, 724.

(52) Hehre, W. J.; Ditchfield, R.; Pople, J. A. The Journal of Chemical Physics 1972, 56, 2257.

(53) Hariharan, P. C.; Pople, J. A. Theoretica chimica acta 1973, 28, 213 (54) Zhao, Y.; Truhlar, D. G. Theoretical Chemistry Accounts 2008, 120, 215

(55) Barone, V.; Cossi, M. The Journal of Physical Chemistry A 1998, $102,1995$.

(56) Cossi, M.; Rega, N.; Scalmani, G.; Barone, V. Journal of Computational Chemistry 2003, 24, 669.

(57) Takano, Y.; Houk, K. N. Journal of Chemical Theory and Computation 2005, 1,70 .

(58) Legault, C. Y.; Université de Sherbrooke: 2009. 
TOC Graphic

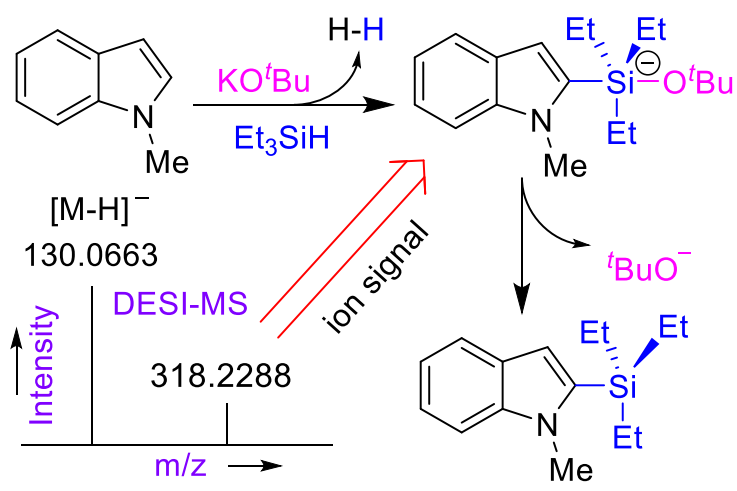

